\title{
RTU Comparison Calculator Enhancement Plan
}

\author{
J. Miller \\ W. Wang \\ S. Katipamula
}

March 2014

\section{Pacific Northwest}

NATIONAL LABORATORY

Proudly Operated by Battelle Since 1965 


\title{
DISCLAIMER
}

United States Government. Neither the United States Government nor any agency thereof, nor Battelle Memorial Institute, nor any of their employees, makes any warranty, express or implied, or assumes any legal liability or responsibility for the accuracy, completeness, or usefulness of any information, apparatus, product, or process disclosed, or represents that its use would not infringe privately owned rights. Reference herein to any specific commercial product, process, or service by trade name, trademark, manufacturer, or otherwise does not necessarily constitute or imply its endorsement, recommendation, or favoring by the United States Government or any agency thereof, or Battelle Memorial Institute. The views and opinions of authors expressed herein do not necessarily state or reflect those of the United States Government or any agency thereof.

\author{
PACIFIC NORTHWEST NATIONAL LABORATORY \\ operated by \\ BATTELLE \\ for the \\ UNITED STATES DEPARTMENT OF ENERGY \\ under Contract DE-AC05-76RL01830 \\ Printed in the United States of America \\ Available to DOE and DOE contractors from the \\ Office of Scientific and Technical Information, \\ P.O. Box 62, Oak Ridge, TN 37831-0062; \\ ph: (865) 576-8401, fax: (865) 576-5728 \\ email: reports@adonis.osti.gov \\ Available to the public from the National Technical Information Service, \\ U.S. Department of Commerce, 5285 Port Royal Rd., Springfield, VA 22161 \\ ph: (800) 553-6847, fax: (703) 605-6900 \\ email: orders@ntis.fedworld.gov \\ online ordering: http://www.ntis.gov/ordering.htm
}


PNNL-23239

\section{RTU Calculator Enhancement Plan}

J. Miller

W. Wang

S. Katipamula

March 2014

Prepared for

U.S. Department of Energy

under Contract DE-AC05-76RL01830

Pacific Northwest National Laboratory

Richland, Washington 99352 


\section{SUMMARY}

Over the past 2 years, the Department of Energy's Building Technologies Office (BTO) has been investigating ways to increase the operating efficiency of the packaged rooftop units (RTUs) in the field -- First, by issuing a challenge to the RTU manufacturers to increase the integrated energy efficiency ratio (IEER) by 60\% over the existing ASHRAE 90.1-2010 standard (Table 1). Second, by evaluating the performance of an advanced RTU controller that reduces the energy consumption by over $50 \%{ }^{1}$.

Table 1: Comparison of ASHRAE Standard 90.1 EER and IEER Requirements with the RTU Challenge Unit Requirements

\begin{tabular}{|l|l|l|l|l|l|l|l|}
\hline \multicolumn{2}{|l|}{ ASHRAE 90.1-2010 } & \multicolumn{2}{l|}{$\begin{array}{l}\text { ASHRAE 90.1-2013 } \\
\text { (before 01/01/2016) }\end{array}$} & $\begin{array}{l}\text { ASHRAE 90.1-2013 } \\
\text { (from 01/01/2016) }\end{array}$ & \multicolumn{2}{l|}{ RTU Challenge Unit } \\
\hline EER & IEER & EER & IEER & EER & IEER & EER & IEER \\
\hline 11.0 & 11.2 & 11.0 & 11.4 & 11.0 & 12.7 & 12.6 & 18 \\
\hline
\end{tabular}

EER = Energy Efficiency Ratio

BTO has previously also funded development of a RTU comparison calculator (RTUCC).

RTUCC is a web-based tool that provides the user with a way to compare energy consumption and costs for two units with different efficiencies. However, the RTUCC currently cannot compare savings associated with either the RTU Challenge unit or the advanced RTU controls retrofit. Therefore, BTO has asked PNNL to enhance the tool so building owners can compare energy and savings associated with this new class of products.

This document provides the details of the enhancements that are required to support estimating energy savings from use of RTU challenge units or advanced controls on existing RTUs.

\footnotetext{
${ }^{1}$ Wang W, S Katipamula, H Ngo, RM Underhill, DJ Taasevigen, and RG Lutes. 2013. Advanced Rooftop Control (ARC) Retrofit: Field-Test Results. PNNL-22656, Pacific Northwest National Laboratory, Richland, WA.
} 


\section{ACKNOWLEDGEMENT}

The authors would like to acknowledge the Buildings Technologies Office of the U.S. Department of Energy (DOE) Office of Energy Efficiency and Renewable Energy for supporting this effort. The authors would also like to thank Amy Jiron and Charles Llenza, Technology Development Managers, at DOE; Nick Fernandez for providing the technical review; Linda Sandahl (Program Manager at PNNL) for thoughtful comments and insights; and Sue Arey for editorial support. 


\section{Contents}

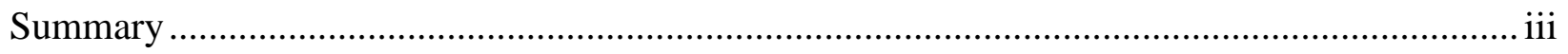

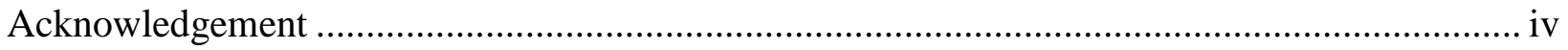

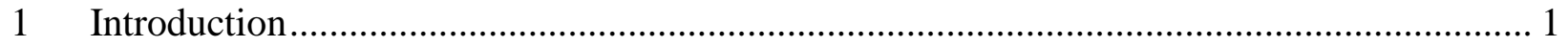

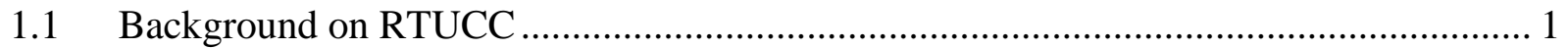

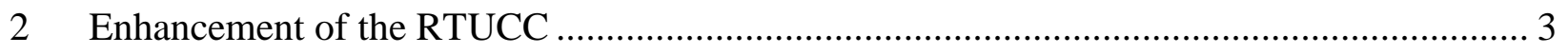

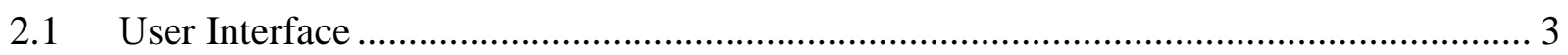

2.2 Algorithmic Changes to the Calculation Engine ......................................................... 4

2.2.1 RTU with Variable-Speed Compressor, and Variable-Speed Supply and Condenser Fans 4

2.2.2 Advanced Rooftop Control (ARC) Retrofit........................................................ 5

2.2.2.1 Integrated Air-Side Economizer Controls .......................................................... 6

2.2.2.2 Supply-Fan Speed Controls ...................................................................... 6

2.2.2.3 The Effects of Fan-Flow Rate on Capacity and Efficiency ............................... 7

2.2.2.4 Cooling Capacity Controls ........................................................................ 8

2.2.2.5 Demand-Controlled Ventilation Controls ..................................................... 8

2.2.3 Three-Stage RTU with Variable Speed Supply and Condenser Fans........................ 8

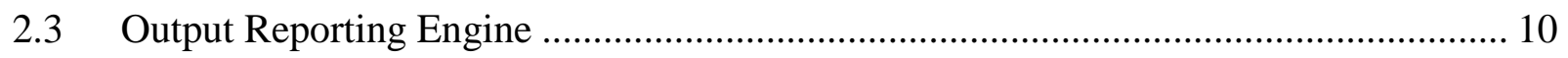

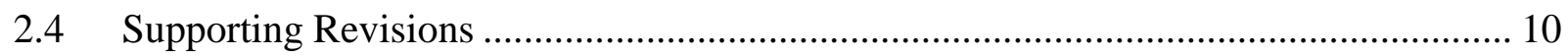

2.4.1 Modeling of the Condenser Fan for General Variable-Speed Units ...................... 10

2.4.2 IEER (Integrated Energy Efficiency Ratio) Calculations...... Error! Bookmark not defined.

2.4.3 General User Interface (UI) Improvements ...................................................... 10

Appendix A: Rules for Retrofit Controls....................................................................... 12

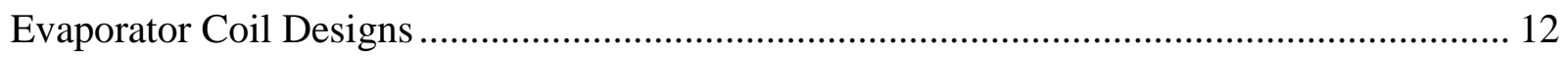




\section{INTRODUCTION}

Packaged rooftop air conditioners and heat pump units (RTUs) are used in 46\% (2.1 million) of all commercial buildings, serving over $60 \%$ (39 billion square feet) of the commercial building floor space in the U.S. (EIA 2003). The primary (source) energy consumption associated with these units is over 1.3 quads. Therefore, even a small improvement in rated efficiency or partload operation of these units can lead to significant reductions of energy use and carbon emissions.

Over the past 2 years, the Department of Energy's Building Technologies Office (BTO) has been investigating ways to increase the operating efficiency of the packaged rooftop units (RTUs) in the field -- First, by issuing a challenge to the RTU manufacturers to increase the integrated energy efficiency ratio (IEER) by 60\% over the existing ASHRAE 90.1-2010 standard (Table 2). Second, by evaluating the performance of an advanced RTU controller that reduces the energy consumption by over $40 \%$.

Table 2: Comparison of ASHRAE Standard 90.1 EER and IEER Requirements with the RTU Challenge Unit Requirements

\begin{tabular}{|l|l|l|l|l|l|l|l|}
\hline \multicolumn{2}{|l|}{ ASHRAE 90.1-2010 } & \multicolumn{2}{l|}{$\begin{array}{l}\text { ASHRAE 90.1-2013 } \\
\text { (before 01/01/2016) }\end{array}$} & $\begin{array}{l}\text { ASHRAE 90.1-2013 } \\
\text { (from 01/01/2016) }\end{array}$ & \multicolumn{2}{l|}{ RTU Challenge Unit } \\
\hline EER & IEER & EER & IEER & EER & IEER & EER & IEER \\
\hline 11.0 & 11.2 & 11.0 & 11.4 & 11.0 & 12.7 & 12.6 & 18 \\
\hline
\end{tabular}

EER = Energy Efficiency Ratio

Majority of building owners are not familiar with the savings the new high efficiency RTU products provide.

BTO has previously funded development of a RTU comparison calculator (RTUCC). RTUCC is a web-based tool that provides the user a way to compare energy consumption and costs for two units with different efficiencies. However, the RTUCC currently cannot compare savings associated with either the RTU Challenge unit or the advanced RTU controls retrofit. Therefore, BTO has funded PNNL to enhance the tool so building owners can compare energy and savings associated with these two new classes of products.

This document provides the details of the enhancements that are required to support estimating energy savings from use of RTU Challenge units or advanced controls on existing RTUs.

\subsection{BACKGROUND ON RTUCC}

RTUCC calculates the run time and energy use of evaporator fans, condenser fans, and compressors as affected by weather, mixed-air and outdoor-air conditions, building type, system type, control strategies, and occupancy schedules. 
Because RTUCC uses a simplified modelling approach, it completes annual energy performance and economic analysis in approximately 1 second, while the detailed hourly simulation programs such as EnergyPlus and DOE-2 could take several minutes.

The RTUCC's short calculation time is achieved by eliminating the dynamic and sequential hour-by-hour modeling of the commercial building. Building envelope, internal, and ventilation loads are estimated in the RTUCC through the use of a representative linear-response model for each in a set of 14 typical-building types ${ }^{2}$. These building models are scaled to match the capacity of the selected RTU at design conditions for the selected city.

The 8,760 hours in a city's weather year are binned by outdoor temperature. Typically between 10 and 20 5-degree temperature bins represent the entire year. This compressed representation of the weather is then used to drive the linear building models and the RTUCC's system simulator.

The simplified building analysis also eliminates the labor needed to specify the details of a building and makes the comparative analysis of RTU units relatively easy.

The end result is a calculation that provides reasonable accuracy for use in comparing the performance of two RTU systems. Absolute predictions of energy use for individual units are best done with detailed hourly building-simulation software.

The rest of this report will discuss the enhancements and changes made to the RTUCC to support advanced controls for RTUs and RTUs with variable-speed fans and compressors. The second set of enhancements relate to the RTU challenge units.

\footnotetext{
${ }^{2}$ Apartment-Mid-Rise, Healthcare-Hospital, Healthcare-Outpatient, Hotel-Large, Office-Small, Office-Medium, Office-Large, Restaurant-Fast Food, Restaurant-Sit Down, Retail-Standalone, Retail-Strip Mall, School-Primary, School-Secondary and Warehouse.
} 


\section{ENHANCEMENT OF THE RTUCC}

The planned enhancements to the RTUCC are discussed in this section. Each subsection presents:

- Brief description of the existing features in the calculator.

- Relevant information on the challenge units or the retrofit controls.

- List of RTUCC modifications needed to support modeling of the retrofit controls and the challenge units.

\subsection{USER INTERFACE}

The calculator's user interface (UI) has a set of user selected inputs for characterizing the two RTU systems being compared. There is also a spreadsheet interface for inputting specific detailed data into the RTUCC for a particular unit.

UI Changes:

- Add a pull-down selection control that has a list with the challenge units and the advanced control retrofit option. The new choices are:

○ RTU with variable-speed compressor, and variable-speed supply and condenser fans

- RTU with three-stage capacity control, and variable-speed supply and condenser fans

- Advanced control retrofit option for standard RTU.

- Add a corresponding help topic for this and any other new controls. Detailed and specific descriptions of the three units will be given there.

- Add a control to adjust the exponent of the power-law model for fans (currently it is fixed at " 3 "). The new control would have a default value of 2.5 and would affect both the candidate and standard units ${ }^{3,4}$.

- The new challenge-unit selection control will trigger scripted setting of corresponding controls:

○ For example selecting the three-stage challenge unit would automatically set the "stages" control to 3 and the "Fan and Compressor" control to "3-Spd: Always on."

\footnotetext{
${ }^{3}$ Chan T. 2004. Beyond the affinity laws. Engineered Systems, August, 2004

${ }^{4}$ Ford R.W. 2011. Affinity laws: why they work and when they don't. ASHRAE Journal 53(3): $42-43$.
} 


\subsection{Algorithmic Changes to the Calculation Engine}

The calculation engine is the core of the RTUCC; it does all the RTU performance and economic analysis calculations and provides the data to the reporting engine. The calculation engine will be modified to accommodate the specific control features and performance curves of the challenge units and the retrofit advanced controls. These features will be coded explicitly in the calculation engine. Changes as needed for each unit are described in the following subsections.

\subsubsection{RTU with Variable-Speed Compressor, and Variable-Speed Supply and Condenser Fans}

RTUCC currently has features for representing variable-capacity rooftop units. The default DOE- 2 capacity and EIR (energy input ratio, which is proportional to the inverse of the coefficient of performance) correction curves are used to model full-load performance of the units. Part-load performance is estimated by scaling capacity and condenser power draw with load fraction (the ratio of sensible load to sensible coil capacity at operating conditions) and using fan affinity laws (cubic power-law relationship) to estimate evaporator-fan power under part-load conditions.

The RTUCC also has a spreadsheet-input interface for entering tabular detailed performance data on the condenser unit, which is then used to fit regression models to establish specific substitutes for the default DOE-2 correction curves. (Note: Also see Section 2.4 on the adaption needed to represent a variable-speed condenser fan.)

\section{Calculation Engine Changes:}

- The variable-speed compressor unit's performance curves (TotalCapTempModFac ${ }^{5}$ ) will be modified to estimate full-load capacity. This modified curve will be generated from test data ${ }^{6}$ that corresponds to full-load operation. This modified curve will be used to determine full-load capacity values at bin conditions. Full-load capacities and corresponding building loads will be used to estimate the load fraction (sensible coil load/sensible coil capacity). Sensible to total capacity splits will be determined with the ADP/BPF (apparatus dew point/bypass factor) method.

\footnotetext{
${ }^{5}$ For more details on these terms please refer to the PNNL report http://www.pnl.gov/main/publications/external/technical_reports/PNNL-22720.pdf

${ }^{6}$ Obtained either obtained from the manufacturers or from manufacturer published data.
} 
Load balance equations will be solved by iteratively searching for the $f f$ value at which the (flow) corrected capacity balances the load. The normal $3^{\text {rd }}$ order polynomial form of TotCapFlowModFac will be used in the capacity correction. During the iterative process sensible capacity is determined with the ADP/BPF method.

This general iterative approach is also used to model the generic variable-capacity unit. The iteration searches for the capacity fraction at which the unit's sensible capacity balances the sensible load. The key differences here are: (1) that the part-load capacity at bin conditions is simply determined by scaling the full-load value by the capacity fraction (no specific modifying curve), and (2) the default DOE-2 curves are used to represent corrections to capacity and EIR as affected by operation conditions.

This $f f$ value will then be used to modify the EIR and capacity corrections to determine the appropriate power consumption of the condenser.

Note: These correction curves fully capture the behavior of the condenser unit. They implicitly represent the two-stage (one variable-capacity stage and one fixed-capacity stage) design and the performance of the condenser fan. There is no need for explicit modeling of the staging or the condenser fan used in this system. (This is similar to the black-box modeling of variable-capacity condensers that is done in the spreadsheet interface.)

- The evaporator fan performance will be estimated with a power-law model using an exponent of 2.5. The model will depend on the $f f$ value established as described above. However, the user will have the ability to select a value other than 2.5 .

- The evaporator fan will run at $40 \%(f f=0.40)$ during times of pure ventilation.

- If the coil load is less than the minimum capacity of the RTU (15\%), the condenser will run less than the full hour. In this case, the run time equals the ratio of the coil load to the minimum capacity. In all other cases, the variable-capacity condenser runs the full hour.

- Performance algorithms will be in separate branches of the calculator code, as triggered by user selection of the variable-speed device.

\subsubsection{Advanced Rooftop Control (ARC) Retrofit}

The RTUCC has features for modeling single-speed, two-speed, and variable-speed fans associated with staged- or variable-capacity compressors. 


\subsubsection{Integrated Air-Side Economizer Controls}

The RTUCC currently models the economizer as integrated. If the economizer cannot satisfy the hourly-bin load, the DX (direct expansion) cooling addresses the remaining sensible load.

\section{Economizer Control Changes:}

- The algorithms supporting the integrated bin-hours will be modified. This change will allow the load in an integrated case to be processed as a trade-off between both pureeconomizer mode (at full fan speed) and pure-DX mode (at normal fan speeds that correspond to the lowest capacity level of the RTU). DX runtimes will be calculated as that fractional balance between these two cooling modes that can satisfy the load. This contrasts with the previous approach where integrated cases where processed with fan at high speed during the duration of the bin hour.

\subsubsection{Supply-Fan Speed Controls}

The RTUCC has features for accounting for a minimum-stop damper setting that corresponds to ventilation flow levels and also accounting for the reduced fan speeds (and associated reduced power draw) when in a pure ventilation mode.

The ARC retrofit adjusts the evaporator fan speed and triggers the stages for a two-stage RTU according to the rules as summarized in Appendix A. The RTUCC is not a time-series based analysis and as a result, must process and completely satisfy the hourly load in each temperature bin. The processing of loads and/or decisions about staging modes cannot in any sense be delayed based on discharge temperature or outdoor conditions.

As a result, the temperature-based rules in Appendix A that would in effect disable stages will not be modeled (i.e., the fan speed will be controlled as indicated in the rule, but the DX cooling will not be disabled). If there is a cooling load, it must be satisfied by the economizer and the condensing unit (one stage, or both if needed).

Essentially, these rules will be represented in the RTUCC by applying the following subset of the fan-speed rules for the RTUCC's two-stage unit using the "1-Spd: Always ON" control mode:

Except for those cases listed below, for two-stage RTUs, the first-stage cooling runs the fan at $75 \%$ and second-stage cooling runs the fan at $90 \%$. Single-stage RTUs address all calls for cooling, running the fan at $90 \%$.

For two-stage RTUs, the first-stage cooling runs the fan at $75 \%$ and second-stage cooling runs the fan at $90 \%$. Single-stage RTUs address all calls for cooling by running the fan at $90 \%$.

- No call for cooling:

- Fan runs at $40 \%$

- Normal operation

- First-stage call:

- $\mathrm{T}>=70 \mathrm{~F}$ : Fan at $75 \%$ 
- T < 70F: Fan at $90 \%$

- Economizer

- Second-stage call: Fan at $90 \%$

- Fan at $75 \%$

- Fan at $90 \%$ (integrated)

\section{Changes:}

- These special conditions for controlling the fan speed will be implemented in separate branches of code in the calculation engine.

- Changes in fan speed affect the effective capacity of the economizer, and also the total capacity and the sensible/total (S/T) ratio of the cooling coils (see Section 2.2.2.3).

\subsubsection{The Effects of Fan-Flow Rate on Capacity and Efficiency}

This type of retrofit fan-speed control will in most cases be installed on an existing one- or twostage row-split RTU with a single-speed fan (see discussion of evaporator design in Appendix A). If retrofit controls are used to reduce the fan speed when either one or both stages are running, the cooling capacity will be reduced. This also produces a colder coil and a corresponding reduction in the sensible/total capacity ratio. This shift toward more latent capacity results in less sensible capacity. Both of these effects reduce the unit's net sensible capacity, which will result in longer run times. The efficiency of the condenser and the corresponding power consumption of the compressor are also affected by the flow change.

Field studies show that there are significant net savings from reducing the fan speeds with the retrofit controls. This is clear evidence that the energy savings from the fan-speed reductions more than compensate for any associated penalty from reduced cooling capacity (and the associated increase in run times).

To account for this in the RTUCC, total-capacity and EIR corrections, as affected by flow rate, will be added to the default curve set. These are available for the existing curves being used.

The RTUCC currently uses an apparatus dew-point and bypass factor (ADP/BPF) method for estimating sensible/total (S/T) ratios at operating conditions. The ADP/BPF method established a characteristic bypass factor based on reported sensible/total ratios at ARI testing conditions. This method can be used to establish $\mathrm{S} / \mathrm{T}$ ratios at various mixed-air conditions including reduced flow rates. (Note that currently the RTUCC is not using this capability to model the S/T splits as affected by varying fan flow because the system reduced its capacity. This simplification is relatively simple to correct and will be done in this release. The current simplification underestimates the sensible capacity in partially loaded conditions for all variable-capacity systems that might be compared with the retrofit case.)

Together, the total-capacity correction curves and the ADP/BPF method can be used to predict the RTU's sensible capacity and power draw at reduced flow rates. 
The reduction of the effective capacity of the economizer must also be accounted for in the RTUCC.

\section{Changes:}

- Change default evaporator representation from face-split (parallel) to the more typical row-split (serial) design.

$\circ$ Use the ADP/BPF method to model the higher S/T ratios that will result for the single-speed fan case when only one compressor is running and cooling capacity is reduced.

- Implement capacity and EIR corrections as a function of fan flow percentage. This must be done for any system changing its fan speed without a corresponding change in condenser capacity.

- Make use of the RTUCC's existing capabilities to model the changes in BPF as affected by changes to capacity and flow rate. This should be used to model the changes to S/T splits for any system that changes its cooling capacity and/or evaporator-fan flow rate, as it adjusts to changing loads.

- Adapt economizer calculations to account for the changes in the evaporator fan flow rate.

\subsubsection{Cooling Capacity Controls}

The RTUCC currently has features for representing staged systems. The algorithms that control the staging modes are driven by the presented load with reference to available cooling capacity in the economizer and the RTU's coil. As needed, loads are addressed by the economizer, the economizer and first-stage cooling, the economizer and both stages, or both stages of cooling. The economizer is enabled for outdoor-air temperatures below set-point.

\section{Changes:}

- None.

\subsubsection{Demand-Controlled Ventilation Controls}

Time-dependent occupancy effects cannot be directly modeled in the binned analysis of the RTUCC. However, a savings percentage could potentially be implemented (inserted) into the economic calculations of the RTUCC. The analysis needed to support the following changes will only be undertaken if time and budget permit.

\section{Changes:}

- Add general energy-savings factor that represents a typical DCV installation.

- Have options in the user interface for the retrofit controls with and without the DCV.

\subsubsection{Three-Stage RTU with Variable Speed Supply and Condenser Fans}

The RTUCC has features for explicit modeling of two equally sized (symmetric) condenser units 
that can be controlled to deliver two stages (capacity levels: 1:A, 2:AA) with either single-speed or two-speed fans. Load is addressed by the smaller stage unless it is overloaded, in which case the leftover load is addressed by the second stage and cycles (and is degraded).

The RTUCC calculates a default split between the condenser power and the evaporator fan power. This is done with a nominal fan-power model as a function of RTU nominal capacity. This model is based on manufacturers' data for a representative set of RTU units. The RTUCC assumes a fan flow rate of $400 \mathrm{cfm}$ per ton.

The new RTU Challenge units could have two asymmetric condenser units that can be controlled to deliver three stage levels (1:A, 2:A, 3:A) with a variable-speed fan.

\section{Changes:}

- Expand the explicit stage modeling to support three stage levels. This new algorithmic approach will be similar to that being used in EnergyPlus. As a multi-stage unit progresses to higher capacity, load will be addressed by its first stage, a pair of intermediate stages, or its highest stage level.

- Change the results page to output a stage-level (SL) indicator that will describe the state of both staged and variable-capacity systems.

- Create default performance curves (capacity and EIR) for each of three stage-capacity levels. All RTU sizes will be modeled with the same set of normalized correction curves (the "generic" set).

- Capacity for each of the three stages will be specified (40\%, 60\%, and 100\%).

- Sensible to total capacity splits will be determined with ADP/BPF method as affected by return air dry-bulb, wet-bulb, and mass flow.

- Nominal evaporator-fan power at $100 \%$ will be estimated.

- Evaporator-fan power for each of three stage levels will be based on a power-law model as a function of stage fraction.

- Condenser power:

○ Condenser power will be calculated as proportional to the capacity (percentage) of each stage

- Alternatively, there could be some consideration given to the likely case that the condenser power will not be split 40/60, as the capacities are.

- The two power levels could be explicitly specified.

- If the split between the compressor and the condenser fan is known, we could estimate the deviation from the 40/60 (i.e., assume the compressor power scales with capacity but that the condenser-fan power follows a power law).

- Specific cycling degradation factor $(15 \%)$ will be automatically selected when this type of unit is selected. 


\subsection{OUTPUT REPORTING ENGINE}

The RTUCC outputs the calculation report to the results web page. This has design conditions, summary of energy and economic analysis, (optionally) detailed bin-calculations, and (optionally) regression-model results from the spreadsheet interface.

To capture and store the details of an RTUCC run, the user does a "save-page-as" from the browser and then picks the "web-page, complete" option.

\section{Changes:}

- Add a parameters summary (parameters as selected on the controls page) to the results page. This will allow capturing all the inputs and results of a particular run on one web page.

\subsection{SUPPORTING REVISIONS}

A number of revisions have been identified based on user feedback. The revisions that will be implemented are described in this section.

\subsubsection{Modeling of the Condenser Fan for General Variable-Speed Units}

\section{Changes:}

- Add functionality to support the calculation of savings related to variable-speed condenser fans. Split out the condenser fan in the controls, calculation engine, and results reporting. Add a "Condenser Fan" help topic and updated related help topics and methods pages.

- Update the spreadsheet to include VisualBasic code that provides capacity and condenser power correction curves for the example RTU. This code also accounts for common partload behaviors: (1) variable-speed condenser and evaporator fans, and (2) cycling degradation for a single-stage unit with a single-speed fan. The correction curves and code can be used to calculate an IEER. These curves, along with fan affinity laws (and cycling degradation factors), can be used to estimate the unit's performance at four representative load-fraction conditions. These four part-load EER values can be aggregated to yield the representative IEER value.

- Update the spreadsheet to include example calculated values in the "EER" and "EERCond" part-load tables on the "Part-load Performance" sheet.. Cells at the top of the "Part-load Performance" sheet will allow users to control the calculations for both variable-speed and non-variable-speed systems.

\subsubsection{General User Interface (UI) Improvements}

The UI improvements that will be made are described in this subsection. 


\section{Changes:}

- Add page-state capture and re-load (from local storage) capability on the controls page to support use of WebKit-type browsers like Google Chrome and Apple Safari. This is necessary to preserve the state of several of the controls when returning to the controls page from the results page.

- Add a feature to preserve the vertical-scroll position of the controls page. This preserves the scroll position when using controls that invoke a resend (regeneration) of the controls page from the server.

- Modify the custom-load model controls to enable viewing the load-model parameters for each of the standard building types. Modify the lock-the-load-line feature so that locking now acts to disable the building-type control and two of the custom model controls. Add a help topic for the custom-load model controls.

- Change the humidity control to be visible whenever the advanced controls are displayed. This is consistent with the approach used with the custom-load model controls.

- Resolve several CSS (style-sheet) formatting issues to improve rendering behavior and speed in the Internet Explorer and Google Chrome browsers. This includes an issue on the report page where one section title is displaced from the intended location.

- Promote the "Stages" control allow individual specification of the number of stages for the candidate and the standard unit. 


\section{APPENDIX A: RULES FOR RETROFIT CONTROLS}

The advanced retrofit campaign (ARC) retrofit adjusts the evaporator-fan speed and triggers the stages for a two-stage RTU according to the following rules:

\section{- No call for cooling:}

If there is no call for cooling (mechanical ventilation only), the fan runs at $40 \%$ with outdoor-air damper at the minimum-stop setting.

- Discharge temperature $\left(T_{d}\right)$ :

○ Very Cold $\left(T_{d}<42^{\circ} F\right) /$ Economizer Only (compressor disabled)

- First-stage call: Fan at $75 \%$

- Second-stage call: Fan at $90 \%$

○ Cold $\left(42^{\circ} \mathrm{F} \leq T_{d}<49^{\circ} \mathrm{F}\right) /$ Integrated

- First-stage call: Fan at 90\% (economizer only; no DX cooling)

- Second-stage call: Fan at 90\% (both stages enabled)

- Outside temperature $\left(T_{o}\right)$ :

○ Cold $\left(T_{o}<58^{\circ} \mathrm{F}\right) /$ Economizer Only (compressor disabled)

- First-stage call: Fan at $75 \%$

- Second-stage call: Fan at $90 \%$

○ Moderate $\left(58^{\circ} \mathrm{F} \leq T_{o}<70^{\circ} \mathrm{F}\right) /$ Integrated

- First-stage call: Fan at 90\% (economizer only; no DX cooling)

- Second-stage call: Fan at $90 \%$

○ Warm $\left(70^{\circ} F \leq T_{o}\right) /$ Integrated

- First-stage call: Fan at $75 \%$

- Second-stage call: Fan at $90 \%$

\section{Evaporator CoIL Designs}

Face-split evaporators essentially have two identical side-by-side coils (not interlaced) and, therefore, require the same flow rate as the unit changes between staging modes. So as the RTU changes from running both stages to only one, the flow (from the single-speed fan) stays constant, maintaining the optimum flow conditions for the single coil (parallel flow continues over the neighboring inactive coil).

In contrast, a two-stage RTU with a row-split (coils are in series) or interlaced (coils are interwoven) evaporator design could have a single-speed or a two-speed fan.

For these row-split units with a two-speed fan, capacity and fan flow rate go up and down together. The $\mathrm{S} / \mathrm{T}$ ratio is roughly preserved as the units changed between staging modes. 
For a row-split units with a single-speed fan, the $\mathrm{S} / \mathrm{T}$ ratio rises significantly when the unit runs only one compressor. Similar fan flow rates with less cooling produce a warmer coil and less latent cooling (dehumidification).

In a similar way, variable-speed systems also modify capacity and fan flow in concert (up and down together). The sensible/total capacity ratio tends to rise to some degree as these systems unload capacity. 


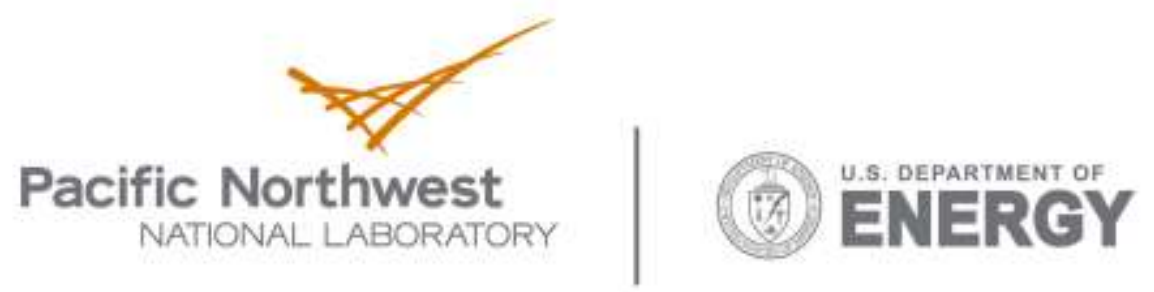

902 Battelle Boulevard

P.O. Box 999

Richland, WA 99352

1-888-375-PNNL (7665)

www.pnl.gov 